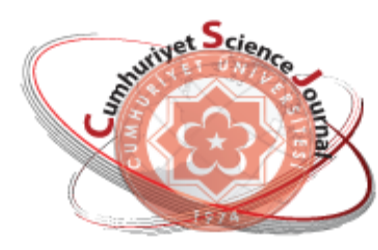

e-ISSN: 2587-246X

ISSN: 2587-2680

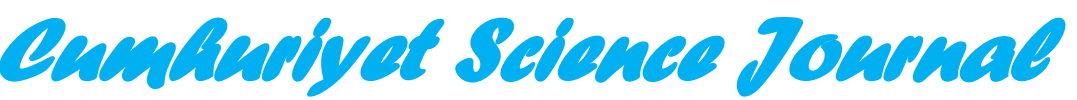

es7

Cumhuriyet Sci. J., Vol.38-3 (2017) 480-487

\title{
The Local Stability Analysis of a Nonlinear Discrete-Time Population Model with Delay and Allee Effect
}

\author{
Figen KANGALGIL \\ Department of Mathematics, Faculty of Sciences, Cumhuriyet University, 58140, Sivas, Turkey \\ Received: 01.03.2017; Accepted: 30.05.2017 \\ http://dx.doi.org/10.17776/csj.340491

\begin{abstract}
In this work, we present a delay general nonlinear discrete-time population model with and without Allee effects which occur at low population density. We investigated local stability conditions of equilibrium point of both models and we compared the local stability of the same equilibrium point of these two models. Obtained all theoretical results were supported by numerical simulations.
\end{abstract}

Keywords: Local Stability Analysis, Allee effect, Equilibrium Point, Population Model.

\section{Gecikmeli ve Allee Etkili Lineer Olmayan Ayrık-Zamanlı bir Popülasyon Modelinin Lokal Kararlılık Analizi}

\begin{abstract}
Özet: Bu çalışmada, genel lineer olmayan ayrık zamanlı gecikmeli bir popülasyon modeli, düşük popülasyon yoğunluğunda ortaya çıkan Allee etkisiyle ve Allee etkisiz olarak ele alınmıştır. Her iki modelin, denge noktasında lokal kararlılık şartları incelendik ve bu iki modelin lokal kararlılıklarını karşılaştırdık. Elde edilen tüm teorik sonuçlar nümerik simülasyonlar ile desteklenmiştir.
\end{abstract}

Anahtar Kelimeler: Lokal kararlılık Analizi, Allee Etkisi, Denge Noktası, Popülasyon Modeli.

\section{INTRODUCTION}

Mathematical models of biological processes and systems are generally expressed in terms of difference or differential equations with or without delay. Difference equations are applied frequently to populations whose generations do not overlap. For example, when adults die and are replaced by their progency, the population size from one generation to the next, $\mathrm{x}_{\mathrm{t}}$ to $\mathrm{x}_{\mathrm{t}+1}$, can be modelled by difference equations. Furthermore, to use models described by difference equations is more efficient for numerical simulations and computations ( see [1-3]). Populations where there is delayed sexual maturation before reproduction may be affected by many previous generations. The effect of the generation $t-T$ which $T$ is the time for sexual maturity on the current generation $t+1$ may be effected by a delayed effect. So, in a population model which is expressed by an difference equation of order $T+1$, the current generation is affected by generations from 1 and $T+1$ generations ago.

In recent years, the study of the Allee effect in population dynamics has become a very important topic in biology and many areas of ecology [4$8,13,14]$. In population models, the Allee effect is often modelled as a threshold, below which there is population extinction. This effect is firstly introduced by Allee in 1931 as "negative density dependence when the growth rate of the population decreases in low population density [9]." The main causes of the Allee effect are the 
difficulty in finding mates, imbreeding depression, social dysfunction at small population sizes, predator avoidance of defence and food exploitation.

In [12], a model was introduced as follow:

$$
N_{t+1}=r N_{t}+f\left(N_{t-T}\right)
$$

where $N_{t}$ is the adult breeding population, $f\left(N_{t-T}\right)$ is the adult stage population with delay of $T$ years and $r$ is the survival coefficient such that $r \in(0,1)$.

In [14], she worked the model (1) with and without Allee effect for the case $T=1$. He concluded that Allee effect either reduces the local stability of equilibrium point of the population model or does not cause any change in it.

In this paper we consider the model (1) for $T=2$ case without and with Allee effect at different times $t, t-1$ and

$t-2$ as follows respectively,

$$
\begin{gathered}
N_{t+1}=r N_{t}+f\left(N_{t-2}\right), r \in(0,1) \\
N_{t+1}=r^{*} N_{t} \alpha\left(N_{t}\right)+f\left(N_{t-2}\right), r^{*}>0
\end{gathered}
$$

where $N_{t}$ is the population density at time $t, r$ is per capita growth rate, the function $f\left(N_{t-2}\right)$ describes interactions among mature individuals and $r^{*}$ is the normalized per capita growth rate given by $\frac{r}{\alpha\left(\mathrm{N}^{*}\right)} \cdot \alpha:=\alpha\left(N_{t}\right)$ is the Allee function at time $t$. and the function $f$ satisfies the conditions (1) and (2) and $r^{*}$ is the normalized per capita growth rate given by $\frac{r}{\alpha\left(\mathrm{N}^{*}\right)} \cdot N^{*}$ is equilibrium point of the model. "The general assumptions on the function $f$ are as follows:

1) $f^{\prime}(\mathrm{N})<0$ for $N \in[0, \infty)$, that is, $f$ continuously decreases as density increases. Biologically, it means that the reproductive output of an individual never increases as the population size increases.

2) $0<f(0)<\infty[4-8,13-15]$.

Also, we consider the model above Eq.(3) which includes the Allee effects. The conclusion of the biological facts requires the following assumption on $\alpha$.

3) If $N=0$, then $\alpha(\mathrm{N})=0$. That is, there is no reproduction without partners.

4) $\alpha^{\prime}(N)>0$ for $N \in(0, \infty)$. Allee effect decreases as density increases.

5) $\lim _{N \rightarrow \infty} \alpha(N)=1$. That is, Allee effect vanishes at high densities [4-8, 13-15].

"The positive equilibrium point of the model which is liable to an Allee effect can become either one of destabilization or of stabilization. Namely, the local stability of a positive equlibrium point can be changed from the stable case to an unstable case or vice versa. It is also possible that even if the model is stable at an equilibrium point, to reach its equilibrium point may take a much longer time. This case has been referred to in the statement that the Allee effect decreases the local stability of the equilibrium point [13]." The aim of this paper is to investigate the local stability analysis of equilibrium solutions of Eq.(2) and Eq.(3) for $T=2$ and to compare the local stability of these models. The remainder of this manuscript is organized as follows: In the following section, we present a characterization of the stability of the positive equilibrium points of Eq.(2) with and without Allee effect. In Section 3 we present some numerical simulations that the analytical results. In the final section we summarize obtained results.

\section{LOCAL STABILITY ANALYSIS}

In this section, we studied the local stability conditions of the positive equilibrium point of 
Eq.(2) and Eq.(3) with Allee effect at different times $t, t-1$ and $t-2$.

Assume that Eqs.(2) and (3) have one positive equilibrium point. Note that, Eq.(2) and Eq.(3) have the same equilibrium point.

\subsection{Local Stability Analysis of Eq. (2)}

Theorem 1 The equilibrium point $N^{*}$ of Eq. (2) is locally stable, if the inequalities

$$
\frac{r-\sqrt{r^{2}+4}}{2}<f^{\prime}\left(N^{*}\right)<\frac{-r+\sqrt{r^{2}+4}}{2}
$$

hold.

Proof. $N^{*}$ be a positive equilibrium point of Eq.(2). By the equilibrium point definition, one has

$$
N^{*}=\frac{f\left(N^{*}\right)}{1-r}
$$

Linearization of Eq. (2) around $N^{*}$ will be

$$
N_{t+1}=r N_{t}+f^{\prime}\left(N^{*}\right) N_{t-2}
$$

So, from Eq. (6) we obtain its characteristic polynomial as follow:

$$
p(\mu)=\mu^{3}-r \mu^{2}-f^{\prime}\left(N^{*}\right)
$$

Then, we write

$$
a_{1}=-r, a_{2}=0, a_{3}=-f^{\prime}\left(N^{*}\right)
$$

We say that $N^{*}$ is locally stable, if

$$
\begin{aligned}
& \left|a_{1}+a_{3}\right|<1+a_{2} \\
& \left|a_{2}-a_{1} a_{3}\right|<1-a_{3}^{2}
\end{aligned}
$$

with the help of Schur-Cohn Criteria[2,3]. From where, we have

$$
\begin{gathered}
f^{\prime}\left(N^{*}\right)+r+1>0, \\
f^{\prime}\left(N^{*}\right)^{2}-r f^{\prime}\left(N^{*}\right)-1<0, \\
f^{\prime}\left(N^{*}\right)^{2}+r f^{\prime}\left(N^{*}\right)-1<0 .
\end{gathered}
$$

If Eqs.(10)-(12) are resolved, inequality (4) is confirmed easily. So the proof is completed.

\subsection{Local Stability Analysis of the Nonlinear Discrete Delay Model (2) with Allee Effect}

We study the stability analysis of the equilibrium points of Eq. (2) with Allee effect at different times $t, t-1$ and $t-2$.

\subsubsection{Allee Effect at Time $t$}

We consider the following nonlinear delay difference equation by the addition of Allee effect to discrete delay model (2)

$$
N_{t+1}=r^{*} \alpha\left(N_{t}\right) N_{t}+f\left(N_{t-2}\right), r^{*}>0
$$

where the function $f$ satisfies the conditions (1) and (2), $\alpha\left(N_{t}\right)$ is Allee function at time $t$.

Then we get the following theorem:

Theorem 2 The equilibrium point $N^{*}$ of Eq. (13) is locally stable if the inequalities

$$
f^{\prime}\left(N^{*}\right)+r \frac{\alpha^{\prime}\left(N^{*}\right)}{\alpha\left(N^{*}\right)} N^{*}+r-1<0,
$$

$$
-f^{\prime}\left(N^{*}\right)-r \frac{\alpha^{\prime}\left(N^{*}\right)}{\alpha\left(N^{*}\right)} N^{*}-r-1<0,
$$

$f^{\prime}\left(N^{*}\right)^{2}+r \frac{\alpha^{\prime}\left(N^{*}\right)}{\alpha\left(N^{*}\right)} f^{\prime}\left(N^{*}\right) N^{*}+r f^{\prime}\left(N^{*}\right)-1<0$,

$f^{\prime}\left(N^{*}\right)^{2}-r \frac{\alpha^{\prime}\left(N^{*}\right)}{\alpha\left(N^{*}\right)} f^{\prime}\left(N^{*}\right) N^{*}-r f^{\prime}\left(N^{*}\right)-1<0$.

hold.

Proof. Likewise, if $\mathrm{a}_{1}, \mathrm{a}_{2}$ and $\mathrm{a}_{3}$ values are calculated for Eq. (13), we obtain

$$
a_{1}=-\left(r+r \frac{\alpha^{\prime}\left(N^{*}\right)}{\alpha\left(N^{*}\right)} N^{*}\right), a_{2}=0
$$




$$
a_{3}=-f^{\prime}\left(N^{*}\right)
$$

If we write the values of $a_{1}, a_{2}$ and $a_{3}$ in the inequalities (8)-(9), we can write

$$
\begin{gathered}
\left|r+r \frac{\alpha^{\prime}\left(N^{*}\right)}{\alpha\left(N^{*}\right)} N^{*}+f^{\prime}\left(N^{*}\right)\right|<1, \\
\left|r f^{\prime}\left(N^{*}\right)+r \frac{\alpha^{\prime}\left(N^{*}\right)}{\alpha\left(N^{*}\right)} f^{\prime}\left(N^{*}\right) N^{*}\right|<1-f^{\prime}\left(N^{*}\right)^{2} .
\end{gathered}
$$

From (20) and (21), one can conclude the result.

\subsubsection{Allee Effect at Time $t$-1}

We now consider model (2) with the Allee effect at time $t-l$ as follows:

$$
N_{t+1}=r^{*} N_{t} \alpha\left(N_{t-1}\right)+f\left(N_{t-2}\right), r^{*}>0 .
$$

Then, we can state the following theorem.

Theorem 3 The equilibrium point $N^{*}$ of Eq. (22) is locally stable if the inequalities

$$
\begin{array}{r}
f^{\prime}\left(N^{*}\right)+r \frac{\alpha^{\prime}\left(N^{*}\right)}{\alpha\left(N^{*}\right)} N^{*}+r-1<0, \\
-f^{\prime}\left(N^{*}\right)+r \frac{\alpha^{\prime}\left(N^{*}\right)}{\alpha\left(N^{*}\right)} N^{*}-r-1<0, \\
f^{\prime}\left(N^{*}\right)^{2}-r \frac{\alpha^{\prime}\left(N^{*}\right)}{\alpha\left(N^{*}\right)} N^{*}+r f^{\prime}\left(N^{*}\right)-1<0, \\
f^{\prime}\left(N^{*}\right)^{2}+r \frac{\alpha^{\prime}\left(N^{*}\right)}{\alpha\left(N^{*}\right)} N^{*}+r f^{\prime}\left(N^{*}\right)-1<0 .
\end{array}
$$

hold.

Proof. According to Eq. (22), $\mathrm{a}_{1}, \mathrm{a}_{2}$ and $\mathrm{a}_{3}$ expressions are as follows:

$a_{1}=-r, a_{2}=-r \frac{\alpha^{\prime}\left(N^{*}\right)}{\alpha\left(N^{*}\right)} N^{*}, a_{3}=-f^{\prime}\left(N^{*}\right)$

If we write the values of $a_{1}, a_{2}$ and $a_{3}$ in the inequalities (8)-(9), we get

$$
\left|r+f^{\prime}\left(N^{*}\right)\right|<1-r \frac{\alpha^{\prime}\left(N^{*}\right)}{\alpha\left(N^{*}\right)} N^{*}
$$

and

$$
\left|r \frac{\alpha^{\prime}\left(N^{*}\right)}{\alpha\left(N^{*}\right)}+r f^{\prime}\left(N^{*}\right)\right|<1-f^{\prime}\left(N^{*}\right)^{2}
$$

So, the proof is completed.

\subsection{Allee Effect at Time $t$-2}

We now incorporate an Allee effect into the discrete delay model (2) as follows:

$$
N_{t+1}=r^{*} N_{t} \alpha\left(N_{t-2}\right)+f\left(N_{t-2}\right), r^{*}>0 .
$$

Then, we can state the following theorem.

Theorem 4 The equilibrium point $N^{*}$ of Eq. (29) is locally stable if the inequalities

$$
\begin{gathered}
f^{\prime}\left(N^{*}\right)+r \frac{\alpha^{\prime}\left(N^{*}\right)}{\alpha\left(N^{*}\right)} N^{*}+r-1<0, \\
-f^{\prime}\left(N^{*}\right)-r \frac{\alpha^{\prime}\left(N^{*}\right)}{\alpha\left(N^{*}\right)} N^{*}-r-1<0, \\
\left(r \frac{\alpha^{\prime}\left(N^{*}\right)}{\alpha\left(N^{*}\right)} N^{*}+f^{\prime}\left(N^{*}\right)\right)^{2}-\left(r^{2} \frac{\alpha^{\prime}\left(N^{*}\right)}{\alpha\left(N^{*}\right)} N^{*}+r f^{\prime}\left(N^{*}\right)\right)-1<0, \\
\left(r \frac{\alpha^{\prime}\left(N^{*}\right)}{\alpha\left(N^{*}\right)} N^{*}+f^{\prime}\left(N^{*}\right)\right)^{2}+\left(r^{2} \frac{\alpha^{\prime}\left(N^{*}\right)}{\alpha\left(N^{*}\right)} N^{*}+r f^{\prime}\left(N^{*}\right)\right)-1<0 .
\end{gathered}
$$

hold.

Prof. According to Eq. (22), $a_{1}, a_{2}$ and $a_{3}$ expressions are as follows:

$a_{1}=-r, a_{2}=0, a_{3}=-\left(r \frac{\alpha^{\prime}\left(N^{*}\right)}{\alpha\left(N^{*}\right)} N^{*}+f^{\prime}\left(N^{*}\right)\right)$

we get by using the inequalities (8)-(9) follows: 


$$
\left|r+r \frac{\alpha^{\prime}\left(N^{*}\right)}{\alpha\left(N^{*}\right)} N^{*}+f^{\prime}\left(N^{*}\right)\right|<1
$$

and

$\left|r^{2} \frac{\alpha^{\prime}\left(N^{*}\right)}{\alpha\left(N^{*}\right)} N^{*}+r f^{\prime}\left(N^{*}\right)\right|<1-\left(r \frac{\alpha^{\prime}\left(N^{*}\right)}{\alpha\left(N^{*}\right)} N^{*}+f^{\prime}\left(N^{*}\right)\right)^{2}$

So, the proof is completed.

Theorem 5 Allee effect at time $t, t-1$ and $t-2$ decreses the stability of the Eq.(2).

Proof. Let's $\quad x=\frac{d f\left(N^{*}\right)}{d N_{t}}<0$ and $y=N^{*} \frac{\alpha^{\prime}\left(N^{*}\right)}{\alpha\left(N^{*}\right)}$. The equation (2) is stable if

$$
x+r+1>0
$$

the following $x^{2}-r x-1<0$

$$
x^{2}+r x-1<0
$$

hold. Similarly, the Eq. (2) with Allee effect at time $t, t-1$ and $t-2$ is stable if, respectively, as follows:

$$
\begin{aligned}
& x+r y+r-1<0, \\
& -x-r y-r-1<0, \\
& x^{2}+r x y+r x-1<0, \\
& x^{2}-r x y-r x-1<0 . \\
& x+r y+r-1<0, \\
& -x+r y-r-1<0, \\
& x^{2}-r y+r x-1<0, \\
& x^{2}+r y+r x-1<0 .
\end{aligned}
$$

and

$$
\begin{aligned}
& x+r y+r-1<0, \\
& -x-r y-r-1<0, \\
& (x+r y)^{2}-\left(r^{2} y+r x\right)-1<0, \\
& (x+r y)^{2}+\left(r^{2} y+r x\right)-1<0 .
\end{aligned}
$$

It is easily seen that the inequalities (37), (38) and (39) are not provided for at least one value $t$ under the inequalities (36) by using Mathematica.

\section{(35) NUMERICAL SIMULATIONS}

In this section, we report on numerical simulations of the presented model with and without Allee effect to support the analytical results obtained in previous sections. We use the Maple for computations and Sigmaplot for graphic arts.

As an example, we consider the functions $f$ and $\alpha$ as follows:

$$
f\left(N_{t}\right)=\frac{1}{N_{t}+1}, \alpha\left(N_{t}\right)=\frac{N_{t}}{a+1}
$$

where $a$ is a positive constant. So, Eqs.(2), (13), (22) and (29) reduce to following forms, respectively.

$$
N_{t+1}=r N_{t}+\frac{1}{N_{t-2}+1}
$$

$$
\begin{gathered}
N_{t+1}=r^{*} \frac{N_{t}^{2}}{a+N_{t}}+\frac{1}{N_{t-2}+1}, \\
N_{t+1}=r^{*} N_{t} \frac{N_{t-1}}{a+N_{t-1}}+\frac{1}{N_{t-2}+1}, \\
N_{t+1}=r^{*} N_{t} \frac{N_{t-2}}{a+N_{t-2}}+\frac{1}{N_{t-2}+1} .
\end{gathered}
$$

where $r>0$ and $. r^{*}=\frac{r}{\alpha\left(N^{*}\right)}$. Figures 1,2 and 3 , we graph the $2 \mathrm{D}$ trajectories of the population dynamics models (2) with and without Allee effect at time $t, t-1$ and $t-2$ for different values of $r=0.5$ and $r=0.7$. So, we conform that The Allee effect decreases the local stability of the equilibrium point of the population model. 


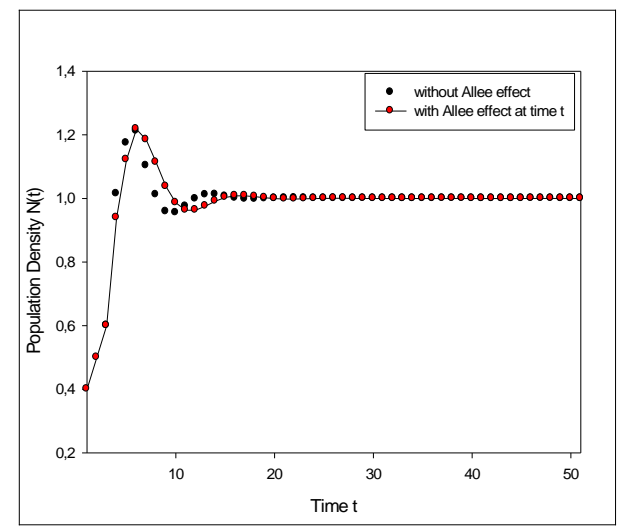

(a)

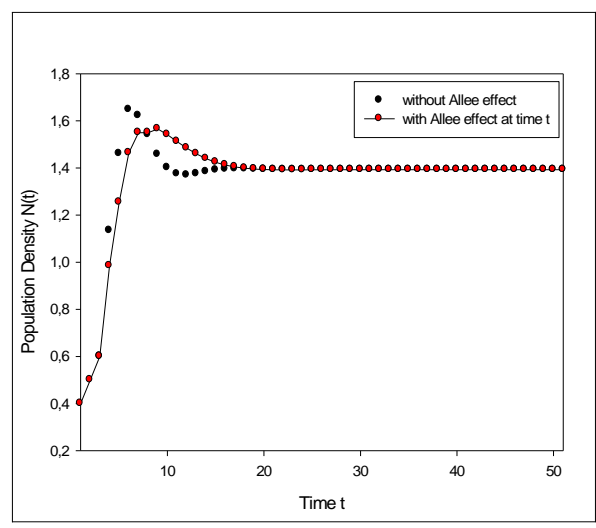

(b)

Figure 1. (a) Density-time graphs of the models (40) and (41) with $r=0.5, N^{*}=1, \alpha=1, \mathrm{r}^{*}=1$ and the initial conditions $N_{-2}=0.4, N_{-1}=0.5, N_{0}=0.6$.

(b)Density-time graphs of the models (40) and (41) with $r=0.7, N^{*}=1.392969449, \alpha=1, \mathrm{r}^{*}=1.202523584$ and the initial conditions $N_{-2}=0.4, N_{-1}=0.5, N_{0}=0.6$.

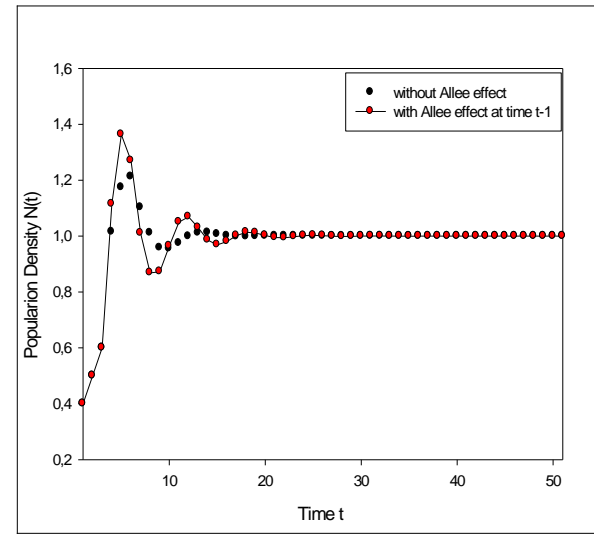

(a)

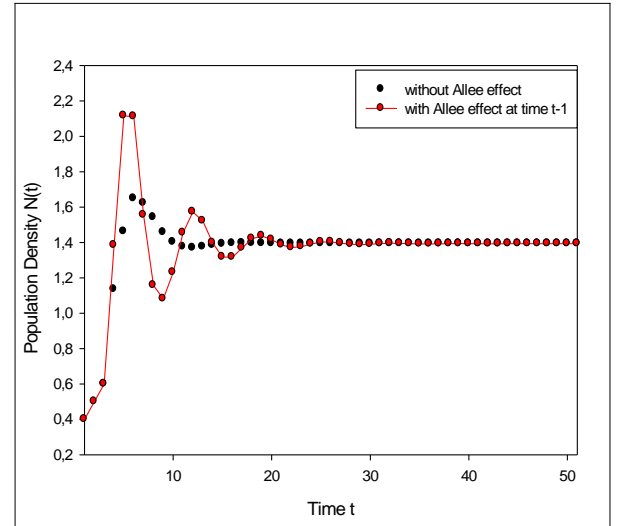

(b)

Figure 2. (a) Density-time graphs of the models (40) and (42) with $r=0.5, N^{*}=1, \alpha=1, \mathrm{r}^{*}=1$ and the initial conditions $N_{-2}=0.4, N_{-1}=0.5, N_{0}=0.6$.

(b)Density-time graphs of the models (40) and (42) with $r=0.7, N^{*}=1.392969449, \alpha=1, \mathrm{r}^{*}=1.202523584$ and the initial conditions $N_{-2}=0.4, N_{-1}=0.5, N_{0}=0.6$. 


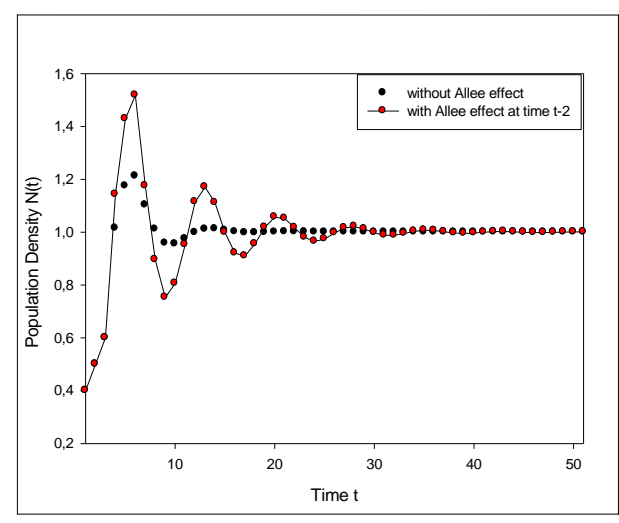

(a)

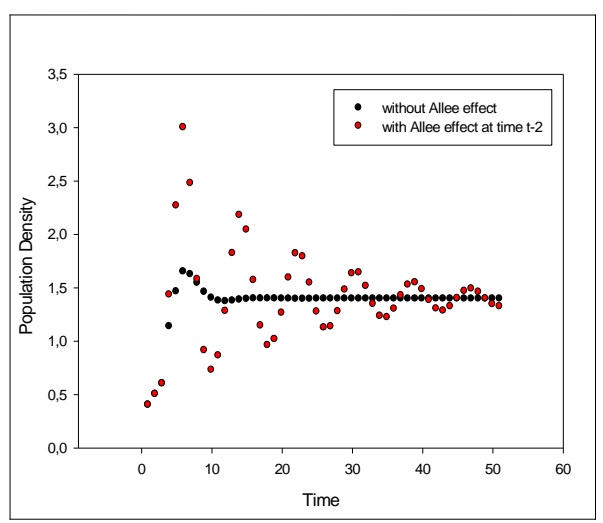

(b)

Figure 3.(a) Density-time graphs of the models (40) and (43) with $r=0.5, N^{*}=1, \alpha=1, \mathrm{r}^{*}=1$ and the initial conditions $N_{-2}=0.4, N_{-1}=0.5, N_{0}=0.6$.

(b)Density-time graphs of the models (40) and (43) with $r=0.7, N^{*}=1.392969449, \alpha=1, \mathrm{r}^{*}=1.202523584$ and the initial conditions $N_{-2}=0.4, N_{-1}=0.5, N_{0}=0.6$.

\section{CONCLUSION}

In this paper, we considered a delay difference population models with and without Allee effect. First, we investigated local asymtotic stability conditions for the equilibrium point of both models. Next, we compared the local stability of the same equilibrium point of these two models. In conclusion, Corallary 1 showed that an Allee effect at different times ( $t, t-1$ and $t-2)$. decreases the local stability of the equilibrium point of Eq. $(<$ ref $>1 d</$ ref $\rangle)$. This result differs from the former one for case $T=1$ [14]. In [14], she concluded that Allee effect either reduces the local stability of equilibrium point of the population model or does not cause any change in it.

\section{Competing Interests}

The authors declare that they have no competing interests.

\section{REFERENCES}

[1]. Y. Kuang, Delay Differential Equations with Applications in Population Dynamics, New York, Academic Press, 1993.

[2]. Allen and J. S. Linda, An Introduction to Mathematical Biology, Texas Tech. University, 2007.
[3]. J. D. Murray, Mathematical Biology, New York, 2002.

[4]. C. Çelik, H. Merdan, O. Duman, Ö. Akın, Allee effects on popülation dynamics with delay, Chaos, Solitons \& Fractals Chaos, 39 (2009), 1994-2001.

[5]. H. Merdan, O. Duman, Ö. Akın, C. Çelik, Allee effects on population dynamics in countinuous (overlapping)case, Chaos, Solitons \& Fractals Chaos, 37 (2008), 6574.

[6]. H. Merdan, O. Duman, On the stability analysis of a general discrete-time population model involving predation and Allee effects, Chaos, Solitons \& Fractals Chaos, 40 (2009), 1169-1175.

[7]. H. Merdan, O. Ak Gumus, Stability analysis of a general discrete-time population model involving delay and Allee effects, Applied Mathematics and Computation, 219 (2012) 1821-1832.

[8]. O. Ak. Gumus, H. Kose, On the stability of delay population dynamics related with Allee effects, Mathematical and Computational Applications, 17 (2012) 5667.

[9]. W.C. Allee, Animal Agretions: A Study in General Sociology, University of Chicago Press, Chicago,1931. 
[10]. F. Brauer, C. Castillo-Chavez, Mathematical models in population biology and epidemiology, 2012.

[11]. O. Ak Gümüş, F. Kangalgil, Allee effect and stability in discrete-time host-parasitoid model, Journal of Advanced Research in Applied Mathematics, 7 (2015), 94-99.

[12]. O. Ak Gumus, Local stability and the Allee effect in nonlinear discrete-time population models with delay, Journal of Advanced Research in Applied Mathematics, 7 (3) (2015) 30-37.

[13]. F. Kangalgil, O. Ak. Gümüş, Allee effect in a new population model and stability analysis, General Mathematics Notes, 35 (1) (2016) 54-64. 